\title{
Influence of Manufacturing Tolerances on PMSM Torque Ripple
}

\author{
P. M. García ${ }^{1,3}$, P. Fernández ${ }^{2,4}$, J. A. Güemes ${ }^{1,4}$, V. Moreno ${ }^{1,3}$, A. M. Iraolagoitia ${ }^{1,4}$, and \\ J. Molina ${ }^{1,3}$ \\ ${ }^{1}$ Department of Electrical Engineering, ${ }^{2}$ Department of Electronic Technology \\ ${ }^{3}$ E.I.G., Plaza Europa 1, 20018 Donostia-San Sebastián (Spain) \\ ${ }^{4}$ E.I.B., Paseo Rafael Moreno "Pitxitxi" 3, 48013 Bilbao (Spain) \\ University of the Basque Country (UPV/EHU)
}

Phone number: +0034 943017234, e-mail: pedromaria.garcia@ehu.eus, pablo.fernandezr@ehu.eus, joseantonio.guemes@ehu.eus, vicente.moreno@ehu.eus, ana.iraolagoitia@ehu.eus, julian.molina@ehu.eus

\begin{abstract}
This work analyzes influence of manufacturing tolerances on permanent magnet synchronous machines (PMSM) behaviour. These tolerances result in imperfections in both final geometry of the machine and composition of material characteristics. The finite element method is used to calculate cogging torque and torque ripple.
\end{abstract}

\section{Key words}

Cogging torque, finite element, permanent magnet, synchronous machines, manufacturing tolerances.

\section{Introduction}

Recently, PMSM are most used in many industrial applications highlighting their easy maintenance, high efficiency or good torque-to-volume ratio, working as motor or as generator.

One of the main problems of PMSM is torque ripple, being source of noise, vibrations, speed ripple and problems for control systems [1]. Minimizing this ripple is very important in the design process. Among causes of torque ripple, one of the most important is cogging torque, result of interaction (magnetic attraction) between magnetic flux from magnets and stator geometry, producing a variable reluctance depending on rotor angular position; therefore it can be said that cogging torque is a characteristic linked to machine design. In the final behaviour of the machine it must be taken into account those effects that, on cogging torque and thus on torque ripple, can have imperfections of production process which, in recent times, have been being studied by various researchers [2]-[6]. Such imperfections or manufacturing tolerances can be grouped into two groups:

- Imperfections in manufacturing process, involving e.g. magnet position errors or eccentricities in the shaft.
- Material imperfections particularly affected by magnetization and also orientation angles of the permanent magnets.

This paper analyzes, using the finite element technique, the effects that imperfections in the manufacturing process and material properties, can have on cogging torque and torque ripple of the machine.

\section{Development}

\section{A) Cogging torque}

Cogging torque can be expressed by the following equation [1], [2]:

$$
T_{\operatorname{cog}}=-\frac{1}{2} \phi_{\mathrm{g}}^{2} \frac{d R}{d \theta}
$$

where $\phi_{\mathrm{g}}$ is magnetic flux density, $R$ is air-gap reluctance and $\theta$ is rotor angular position. Since reluctance varies periodically, it can be expressed as a Fourier series [7][8]:

$$
T_{\mathrm{cog}}=\sum_{k=1}^{\infty} T_{\mathrm{mk}} \operatorname{sen}(m k \theta)
$$

where, $T_{\mathrm{mk}}$ is the amplitude of each component of the series, $m$ is the least common multiple between the number of stator slots and pole number of the machine and $k$ is an integer. It can be proved that the number of cogging torque cycles per revolution of the rotor is equal to $m$.

Given the cyclical nature of cogging torque is not necessary to study a full rotation of rotor, reducing the study to smaller angles, for example, one stator slot pitch angle. The number of periods of cogging torque during rotation of one slot pitch $(N)$ can be determined using [9]: 


$$
N=\frac{2 p}{\operatorname{GCD}(2 p, Q)}
$$

where GCD is the greatest common divisor between number of poles $(2 p)$ and slots $(Q)$.

\section{B) Torque Ripple}

Electromagnetic torque is calculated by simulating the machine behaviour on load conditions. For this, stator winding is excited with balanced three-phase sinusoidal currents to produce a magnetomotive force rotating at synchronous speed. The relative position of the wave with respect to the rotor has been previously calculated to obtain the maximum torque.

After obtaining a cycle of electromagnetic torque, ripple factor $(R F)$ and cogging factor $(C F)$ are used to study the effect of different variables on torque ripple. These are defined as:

$$
\begin{aligned}
& R F(\%)=\frac{T_{\text {max }}-T_{\min }}{T_{\mathrm{av}}} 100 \\
& C F(\%)=\frac{C_{\mathrm{max}}-C_{\min }}{T_{\mathrm{av}}} 100
\end{aligned}
$$

where $T_{\max }, T_{\min }$ and $T_{\mathrm{av}}$ are the maximum, minimum and average values of electromagnetic torque, and $C_{\max }$ and $C_{\min }$ the minimum and maximum values of cogging torque.

\section{Machines and models}

The machine used in this work is a surface magnets type. To reduce cogging torque, magnets are skewed an angle equal to one slot pitch. Main features of the machine are shown in Table I.

TABLE I. Details of the analyzed motors.

\begin{tabular}{|l|c|}
\hline Regulator input voltage (V) & 400 \\
\hline Number of poles & 6 \\
\hline Number of stator slots & 18 \\
\hline Permanent magnet material & $\mathrm{NdFeB}$ \\
\hline Magnet angle $\left(^{\circ}\right)$ & $50^{\circ}$ \\
\hline Magnet length $(\mathrm{mm})$ & 24 \\
\hline
\end{tabular}

Analysis has been performed by FLUX Skewed module that allows in 2D models to introduce the effect of the inclination of magnets.

Two different simulations were performed:

- No stator currents. Such simulation allows calculation of cogging torque. In this simulation it is enough to perform models that incorporate machine geometry and properties of different materials. Figure 1 shows the mesh model used.

- With stator currents. In this simulation used to analyze the torque ripple of the machine, in addition to the geometry and the materials properties, there must be a model of the electric circuit with the number of turns, resistance of each phase, or end-winding induction. This allows torque calculation on load conditions.

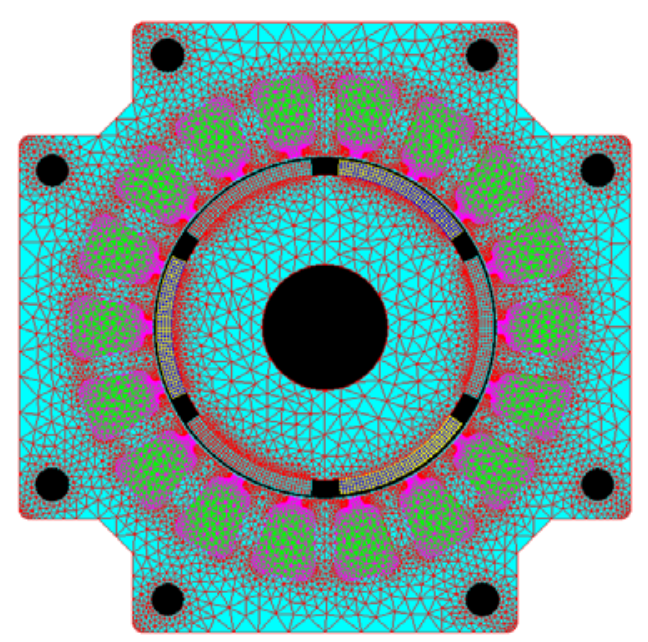

Fig. 1. Model and mesh type used for machine analysis.

\section{Results}

In this section, results of the influence of different factors on cogging torque and torque ripple are shown.

The factors analyzed are:

- Variations in the geometry of the magnets (angle occupied by the magnet, magnet thickness and inclination angle of the magnet).

- Variations in the physical properties of the magnet (relative permeability and remanent flux density).

\section{A) Influence of angle occupied by magnets}

Angle occupied by magnets is an important factor to be considered in the motor design process,. For definition of this angle, some researchers [1], [7] suggest the expression:

$$
\alpha_{m}=\frac{n+v}{N_{s m}}<1, \quad 0<v<1
$$

where $\alpha_{m}$ is relation between angle occupied by magnets and polar arc, $n$ is an integer number, $N_{s m}$ is number of slots per pole and $v$ is a coefficient for cogging torque reduction. For every $n$ value, there is a set of $i$ different values of $v$ to minimize $i$ order harmonics of cogging torque.

This analytic expression is not enough to calculate the angle to be occupied by magnets, so usually finite element method is used. In this paper, motor behaviour with angle occupied by magnets between $47^{\circ}$ and $53^{\circ}$, with a step of $0.5^{\circ}$ is studied.

Figure 2 shows the influence on cogging torque. Angle range represented in the graph, corresponds to the angle studied (one stator slot pitch). 


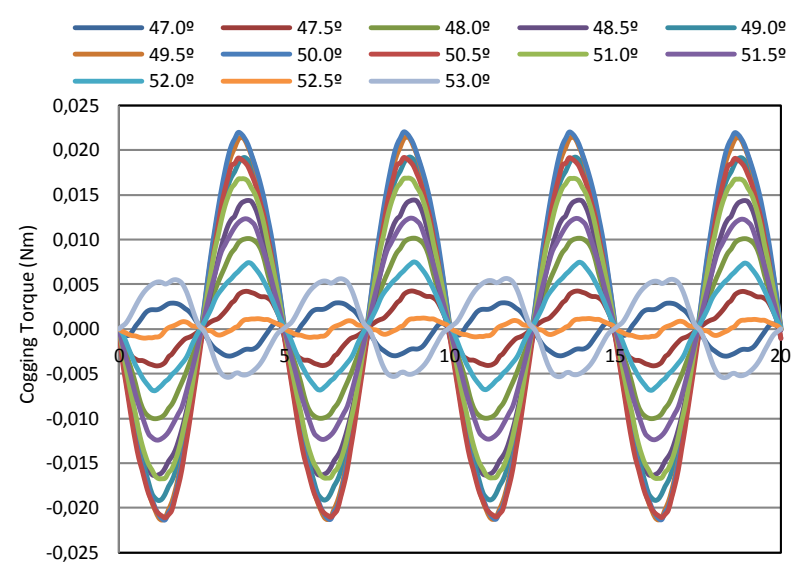

Fig. 2. Influence of the angle occupied by magnets on cogging torque.

Figure 3 shows variation of peak-to-peak cogging torque.

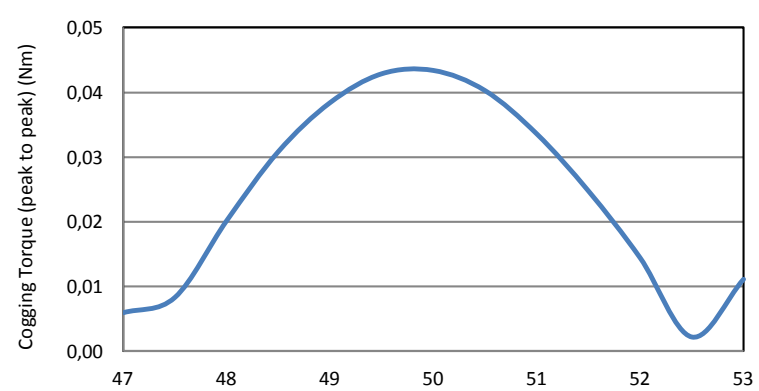

Fig. 3. Influence of the angle occupied by magnets on peak-topeak cogging torque.

Figures 4 and 5 show the effect of the angle occupied by magnets on average torque and torque ripple.

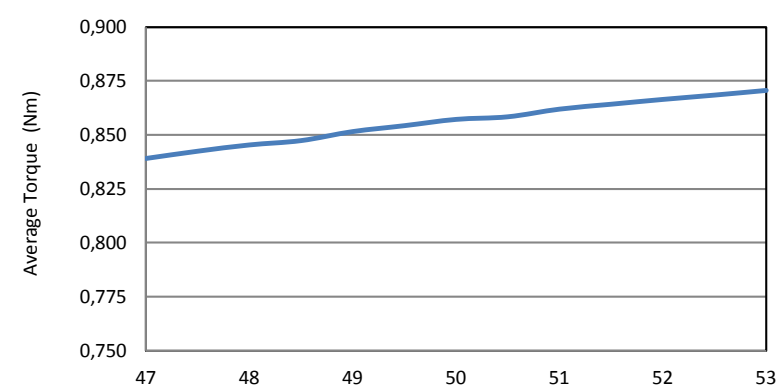

Fig. 4. Influence of the angle occupied by magnets on average torque.

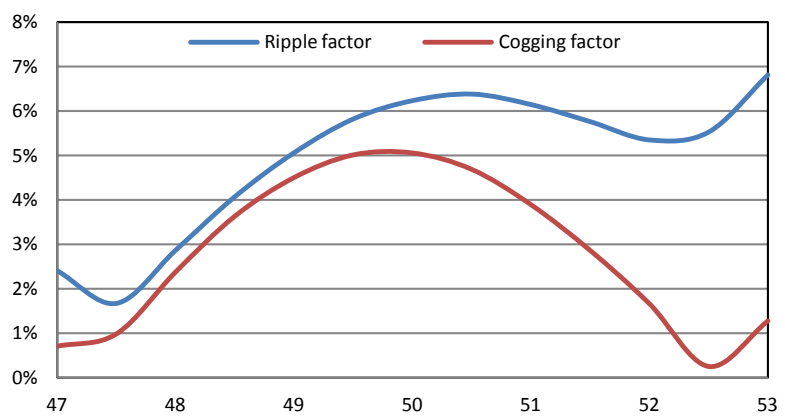

Fig. 5. Influence of the angle occupied by magnets on torque ripple.
Results show that:

- the angle occupied by the magnets has a significant influence on cogging torque, average torque and torque ripple;

- ripple and cogging factors have a maximum value for a $50^{\circ}$ occupation angle, coinciding with the maximum found for cogging torque;

- cogging factor has a minimum for $52.5^{\circ}$, while ripple factor has a minimum for $47.5^{\circ}$; it is clear that a low cogging factor not always means reduced ripple factor.

\section{B) Influence of magnet skewing angle}

Second geometric factor studied is magnet skewing angle. FEM simulations have been performed with skewing angles between $17^{\circ}$ and $23^{\circ}$, with a step angle of $1^{\circ}$.

Effect of cogging torque is shown on Figure 6.

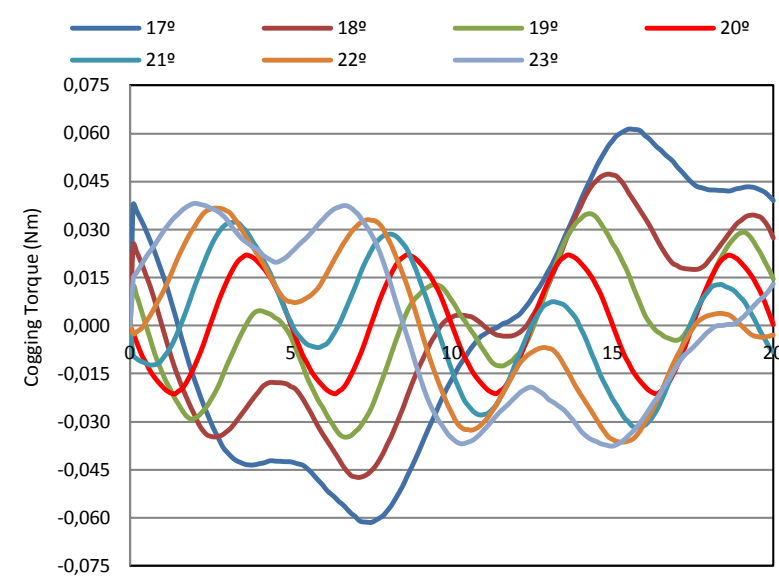

Fig. 6. Influence of magnet skewing angle on cogging torque.

Figure 7 shows variation of peak-to-peak cogging torque.

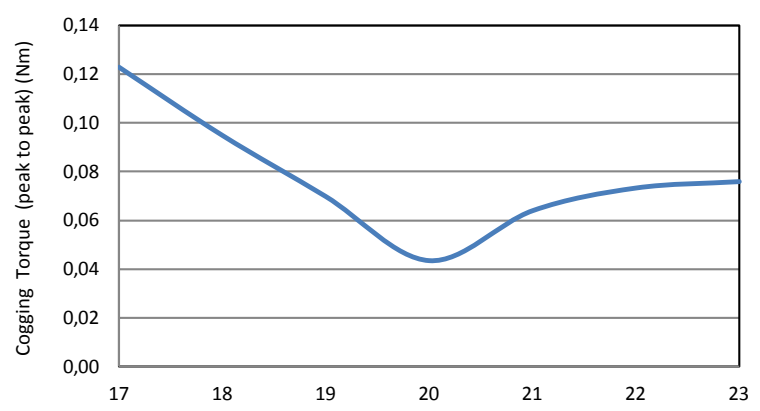

Fig. 7. Influence of magnet skewing angle on peak-to-peak cogging torque.

Figures 8 and 9 show the effect of magnet skewing angle on average torque and torque ripple. 


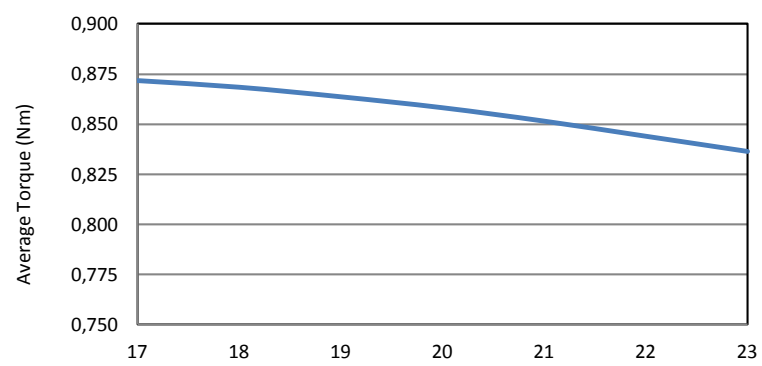

Fig. 8. Influence of magnet skewing on average torque.

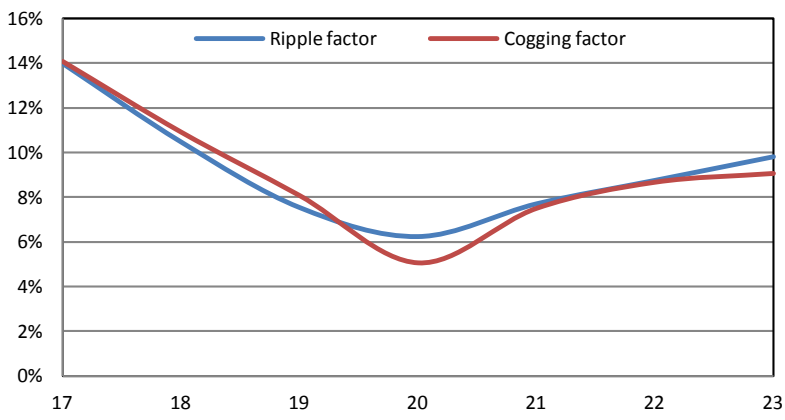

Fig. 9. Influence of magnet skewing angle on torque ripple.

Results show:

- magnet skewing angle has important effect on cogging torque, average torque and torque ripple;

- analytical results are confirmed, since lowest cogging torque, $C F$ and $R F$ are obtained with a skewing angle of $20^{\circ}$, corresponding to one stator slot pitch and one cycle of cogging torque;

- average torque is reduced when magnet skewing angle rises.

\section{C) Influence of magnet thickness}

Third geometric factor studied is magnet thickness. Beginning with $2.5 \mathrm{~mm}$, simulations are performed to study variations between 2.3 and $2.7 \mathrm{~mm}$ with a step of $0.05 \mathrm{~mm}$.

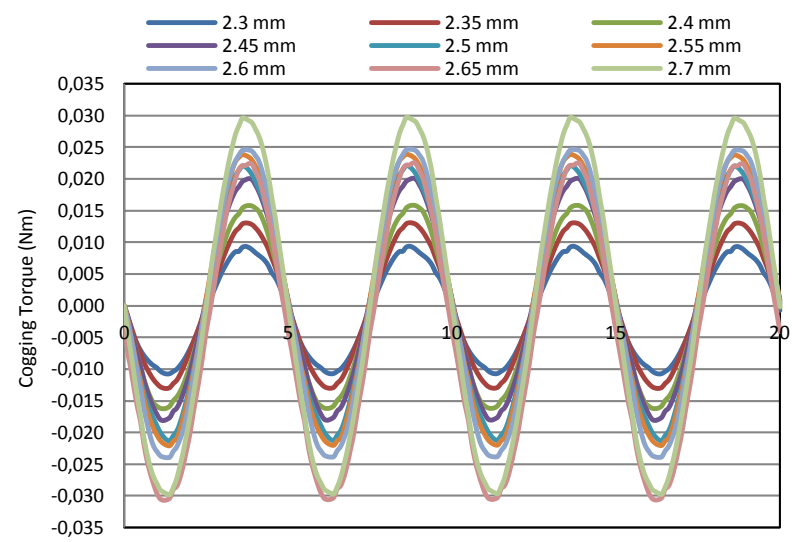

Fig. 10. Influence of magnet thickness on cogging torque.

Figures 10, 11, 12 and 13, respectively, show effect of magnet thickness variation on cogging torque, peak-topeak cogging torque, average torque and torque ripple.

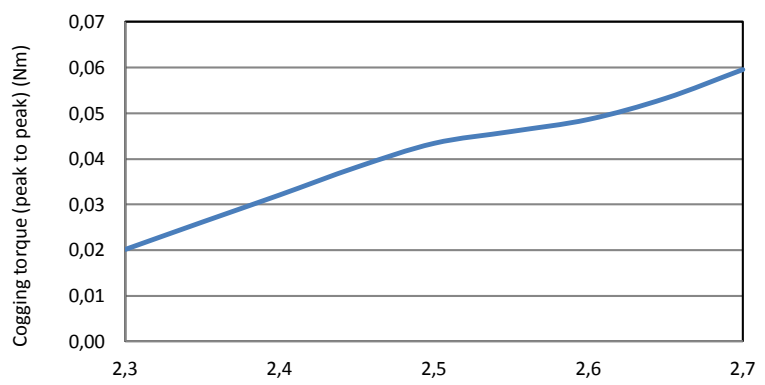

Fig. 11. Influence of magnet thickness on peak-to-peak cogging torque.

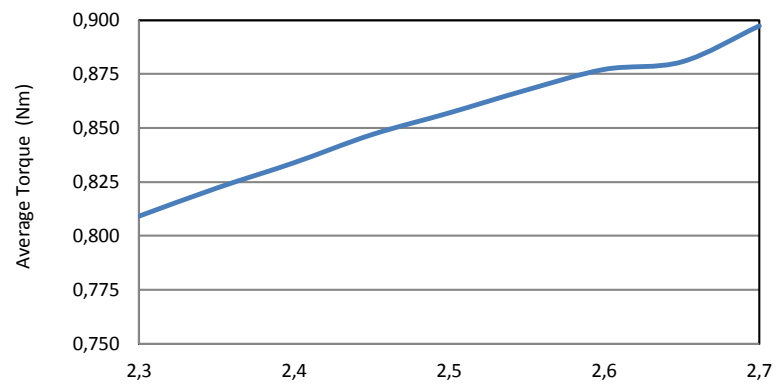

Fig. 12. Influence of magnet thickness on average torque.

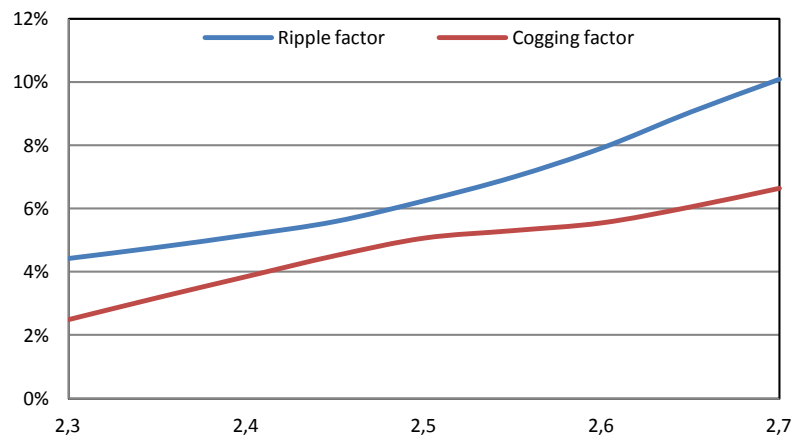

Fig. 13. Influence of magnet thickness on torque ripple.

Results show that:

- there is a direct relationship of magnet thickness not only with cogging torque, but also with average torque and torque ripple (rising with magnet thickness).

\section{D) Influence of relative permeability}

In this section, influence of relative permeability of magnets on motor behaviour is studied.

Motor performance analysis is developed with $\mu_{\mathrm{r}}$ relative magnetic permeability between 0.9 and 1.2 , with a step of 0.5 .

Figures 14, 15, 16 and 17, respectively, show influence of magnet relative permeability on cogging torque, peakto-peak cogging torque, average torque, cogging factor and ripple factor. 


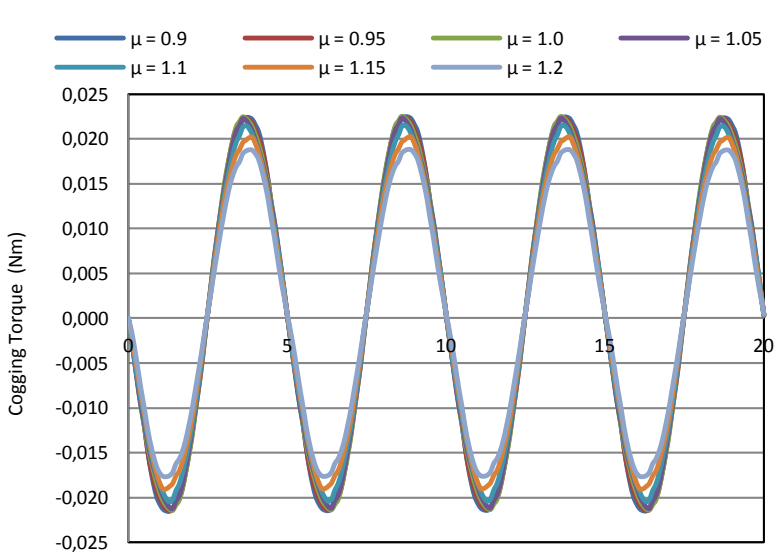

Fig.14. Influence of relative permeability on cogging torque.

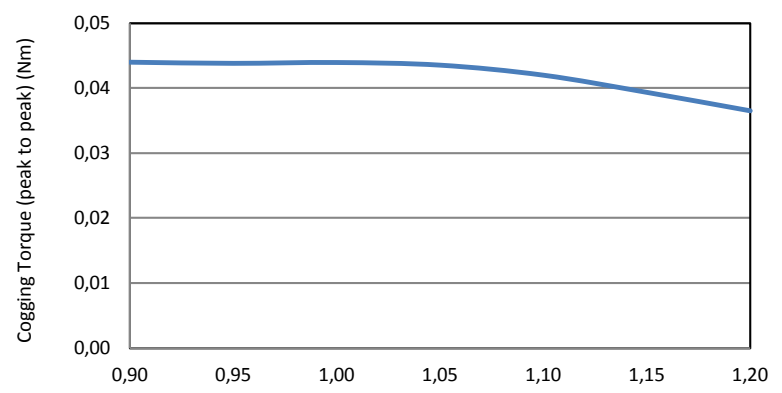

Fig.15. Influence of relative permeability on peak-to-peak cogging torque.

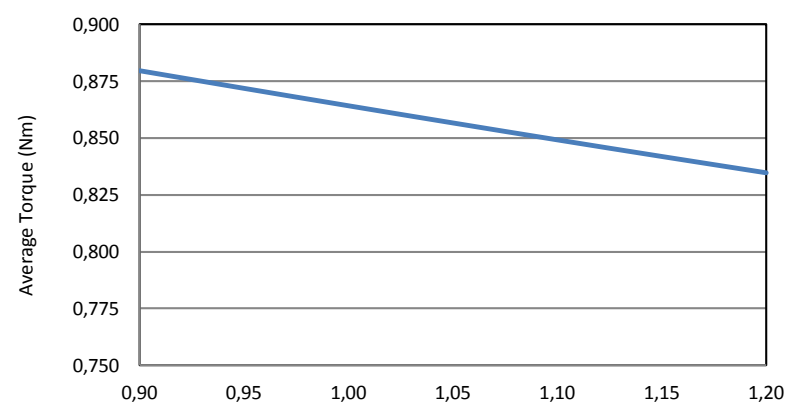

Fig.16. Influence of relative permeability on average torque.

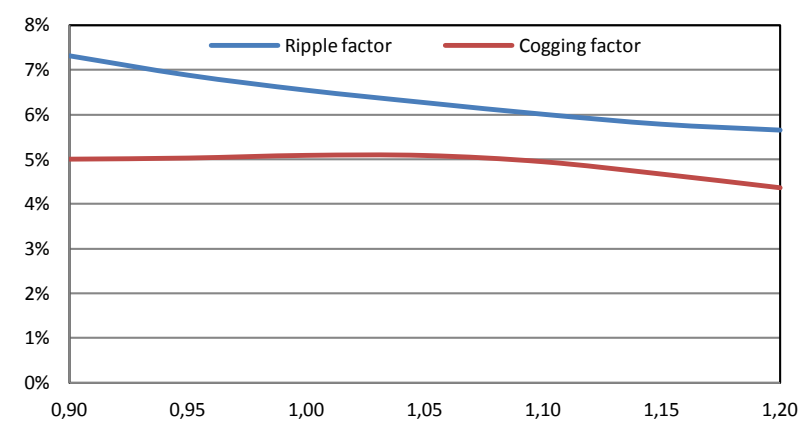

Fig.17. Influence of relative permeability on ripple and cogging factors.

Results show that:

- variations of relative permeability have minimum effect on cogging torque, but a slightly higher effect on ripple factor;

- average torque is lower when relative permeability increases.

\section{E) Influence of magnet remanent flux density}

In this section, influence of remanent magnetization of magnets on motor performance is studied. Motor analysis is performed with a remanence range between $1.0 \mathrm{~T}$ and $1.2 \mathrm{~T}$, with a step of $0.5 \mathrm{~T}$.

Figures 18, 19, 20 and 21, respectively, show influence of remanent flux density on cogging torque, peak-to-peak cogging torque, average torque and torque ripple.

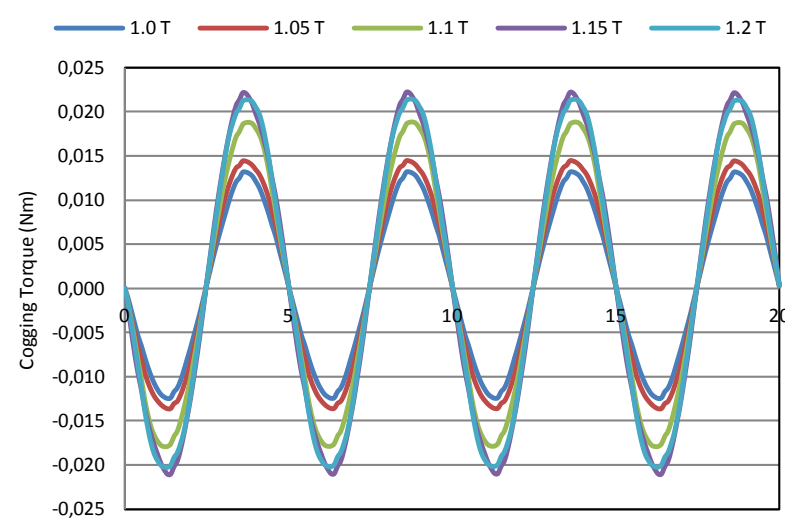

Fig. 18. Influence of magnetic remanence on cogging torque.

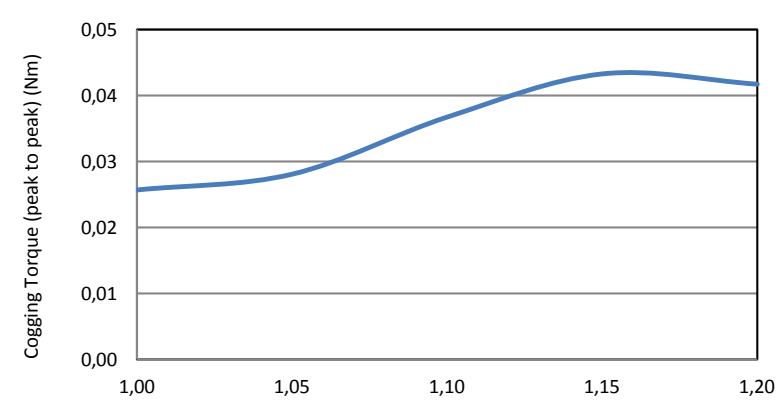

Fig. 19. Influence of magnetic remanence on peak-to-peak cogging torque.

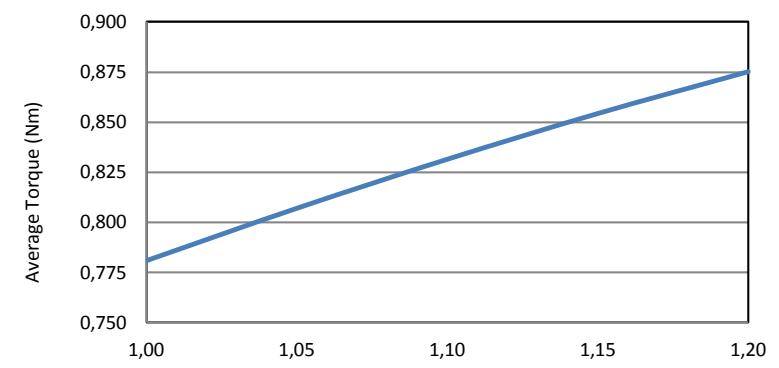

Fig. 20. Influence of magnetic remanence on average torque.

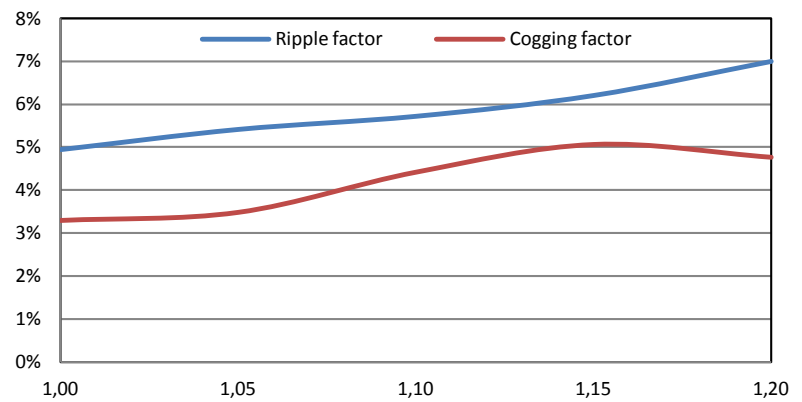

Fig.21. Influence of magnetic remanence on ripple and cogging factors. 
Results show that:

- influence of magnetic remanence on cogging torque is significantly higher than relative permeability influence;

- Average torque and ripple and cogging factors show a direct relationship with magnets remanent flux density.

\section{Conclusions}

Using the finite element method, influence that imperfections due to tolerances inherent to any manufacturing process have in the behaviour of a PMSM is studied. This influence, difficult to calculate by methods different to finite element, allows design optimization, and product cost reduction by reducing development time and number of prototypes.

Knowing the most critical parameters on torque ripple, will help us to take decisions about final geometry, material quality or set adequate quality controls.

Possible defects in machine geometry and magnet quality (physical properties) have been taken into account as study variables. Effects on cogging and ripple factors have been used to analyze motor behaviour.

Variations of magnet properties (relative permeability and remanent flux density) have a more controllable effect, with an almost linear relationship with the factors used for comparison, as well as with average torque. Of the two variables, remanent flux seems to have greater influence.

Unlike magnetic factors, influence of geometric factors is less predictable and small variation can lead to significant change of ripple and cogging factors.

This is especially true for the first two variables. Both, the angle occupied by magnets and skew angle have an important influence on cogging torque and torque ripple, with significant variations of ripple and cogging factor. Small differences of this angle can have non-desired effects on motor performance.

\section{References}

[1] L. Dosiek and P. Pillay, "Cogging torque reduction in permanent magnet machines", IEEE Transactions on Industry Application, vol. 43, no. 6, pp. 1656-1571, 2007.

[2] I. Coenen, M. van der Giet and K. Hameyer, "Manufacturing Tolerances: Estimation and Prediction of Cogging Torque Influenced by Magnetization Faults", IEEE Transactions on Magnetics, vol. 48, no. 5, pp. 19321936, May. 2012.

[3] L. Gasparin, A. Cernigoj, S. Markic and R. Fiser, "Additional Cogging Torque Components in PermanentMagnet Motors Due to Manufacturing Imperfections", IEEE Transactions on Magnetics, vol. 45, no. 3, pp. 12101213, Mar. 2009.

[4] M. A. Khan, I. Husain, M. R. Islam and J. T. Klass, "Design of Experiments to Address Manufacturing Tolerances and Process Variations Influencing Cogging Torque and Back EMF in the Mass Production of the Permanent-Magnet Synchronous Motors", IEEE Transactions on Industry Applications, vol. 50, no. 1, pp. 346-355, Jan./Feb. 2014.

[5] V. Simón Sempere, M. Burgos Payán and J. R. Cerquides Bueno, "Influence of Manufacturing Tolerances on the Electromotive Force in Permanent-Magnet Motors", IEEE Transactions on Magnetics, vol. 49, no. 11, pp. 5522-5532, Nov. 2013.

[6] S. Lee, K. Kim, S. Cho, J. Jang, T. Lee and J. Hong, "Optimal Design of Interior Permanent Magnet Synchronous Motor Considering the Manufacturing Tolerances Using Taguchi Robust Design”, IET Electric Power Applications, vol. 8, lss. 1, pp. 23-28, 2014.

[7] Z. Q. Zhu, "Influence of Design Parameters on Cogging Torque in Permanent Magnet Machines". IEEE Transactions on Energy Conversion, vol. 15, no. 4, pp. 407-412, 2000.

[8] Z. Q. Zhu, S. Ruangsinchaiwanich and D. Howe, "Synthesis of cogging-torque waveform form analysis of a single stator slot", IEEE Transactions on Industry Applications, vol. 42, no. 3, pp. 650-657, 2006.

[9] D. A. González, J. A. Tapia and A. Letelier, "Desing Consideration to Reduce Cogging Torque in Axial Flux Permanent-Magnet Machines”, IEEE Transactions on Magnetics, vol. 43, no. 8, pp. 3435-3440, 2007. 